\title{
SONDAS CULTURAIS COMO MÉTODO PARA A CRIAÇÃO DE DADOS EM PESQUISAS COM CRIANÇAS
}

Sílvia Fernanda de Medeiros Maciel ${ }^{(*)}$

O uso de sondas culturais, como estratégia de criação de dados de pesquisa sobre produção de sentidos na vida cotidiana com crianças, surge como um caminho metodológico capaz de fazer crianças se engajarem no jogo da pesquisa com interesse e prazer. Esta estratégia metodológica para a criação de dados busca se distanciar, o mais possível, das limitações oriundas da "não partilha de significado linguístico entre o experimentador e a criança" (LOURENÇO, 1999, p.258) e se baseia na ideia de que a "identificação empática com o outro [...] ajuda o observador a ver um sentido no que o outro está fazendo" (HARRÉ \& GILLETT, 1999, p.25). As sondas culturais revelam-se, então, como um método que se situa no espaço intersubjetivo entre pesquisador, criança e o objeto da investigação.

Neste artigo, apresentamos o que são as sondas culturais e as situamos como uma estratégia metodológica inovadora de criação de dados para pesquisas em psicologia. Especificamente, apresentamos dados de uma pesquisa realizada com crianças, para estudo dos sentidos da vida cotidiana, desenvolvida a partir do uso do recurso da fotografia em um jogo de pesquisa.

\section{DO DESIGN PARA A PSICOLOGIA}

Sondas culturais (GAVER, DUNNE \& PACENTI, 1999) são instrumentos de criação de dados nascidos na área do design da interação que, como as sondas astronômicas, oceânicas ou cirúrgicas, são enviadas para onde se quer investigar e retornam, tempos depois, com informações que ajudam a responder às questões dos pesquisadores. Esses instrumentos apontam para a possibilidade de uma produção de dados centrada no sujeito, notadamente individual e o mais autônoma possível (MATTELMÄKI, 2006).

\footnotetext{
(*) Professora adjunta do Departamento de Psicologia da Universidade Federal de Pernambuco (UFPE). Professora colaboradora do Programa de Pós-Graduação em Psicologia Cognitiva da UFPE. Graduada em Psicologia, mestre em Letras e Linguística e doutora em Psicologia Cognitiva Desenvolve atividades de ensino e pesquisa nas áreas de Psicologia do Desenvolvimento, Educação e Saúde. E-mail: silviamaciel.psicologia@gmail.com.
} 
Os primeiros registros de projetos com sondas culturais nasceram no fim da década de 1990, na área do design (GAVER, DUNNE \& PACENTI, 1999; MATTELMÄKI, 2006). Esses trabalhos levavam em conta, fundamentalmente, as emoções e a experiência das pessoas, no que diz respeito a sua relação com o design de produtos aos quais eram apresentadas. $\mathrm{O}$ estudo de Gaver, Dunne e Pacenti (1999) tinha como objetivo explorar tecnologias para apoiar a ampliação da presença ativa de idosos em comunidades locais (especificamente nas cidades Peccioli, na Itália, Oslo, na Noruega e Amsterdam, na Holanda); nele, os pesquisadores entregaram um kit para a produção de dados (um pacote plástico contendo câmera fotográfica descartável, cartões postais, mapas da cidade, álbum de fotografia, diário, lápis, caneta e instruções), a um grupo de pessoas idosas - depois de uma conversa em que lhes deram orientações sobre como registrar as solicitações dos pesquisadores e sobre como lhes enviar os dados (GAVER, DUNNE \& PACENTI,1999).

As sondas foram, então, inicialmente elaboradas para traçar o perfil de grupos específicos e, consequentemente, gerar informações sobre esta população para a criação de produtos a ela dirigidos. Surgiram como "parte de uma estratégia que buscava traçar o delineamento experimental de uma maneira sensível" (GAVER, DUNNE \& PACENTI, 1999, p.22) na área do design da interação. A ideia era a de proporcionar aos sujeitos da investigação, mecanismos para que eles registrassem aspectos de suas vidas ou de sua relação com algum tema ou tecnologia. Com esse “espírito experimental” (MATTELMÄKI, 2006), a instrução básica para a utilização das sondas é: "aplique-a", ou talvez melhor dizendo, "use-a".

Refletindo sobre a concepção das sondas, surge o questionamento sobre o porquê de não usar os métodos tradicionais já existentes para a criação dos dados - visto que com eles, os pesquisadores poderiam alcançar os mesmos objetivos. A esta questão, os pesquisadores (GAVER, DUNNE \& PACENTI, 1999) respondem dizendo que queriam um material capaz de fazer falar de sonhos, medos e esperanças das pessoas - noutros termos, os autores queriam um material com possibilidades de provocar efeitos de subjetivação nas pessoas. Além disso, criaram as sondas porque não queriam, entre outras coisas, limitar as possibilidades de diálogo com os sujeitos da pesquisa (o que, em seu ponto de vista, aconteceria com o uso de questionários, por exemplo), nem remover sua própria identidade de todo esse processo.

O que sabemos, portanto, é que, desde as primeiras sondas culturais, foram registradas diversas mudanças no campo do design centrado no usuário. As pesquisas nesta área abandonaram uma perspectiva metodológica tradicional e, em função dos desafios propostos, as sondas surgiram como uma possibilidade de atender a demandas de compreensão e experimentação 
(MATTELMÄKI, 2006). A postura sugerida ao pesquisador nessa área era a de procurar "ouvir o que as pessoas dizem, olhar o que elas fazem e deixar que elas expressem o que pensam e sonham" (MATTELMÄKI, 2006, p.29), de forma criativa - "de certa forma, como os testes projetivos [...]: sugestivos, mas ambíguos" (GAVER, 2001).

As sondas, portanto, podem ser definidas basicamente por três pontos (MATTELMÄKI, 2006, p.40). Primeiro, são "baseadas na participação do usuário por meio da autodocumentação", com elas as pessoas registram suas experiências, pensamentos, ideias, etc. Segundo, são construídas com o objetivo de "descrever os fenômenos humanos", tendo como foco o contexto pessoal do seu usuário (seu cotidiano, os lugares pelos quais transitam, suas interações, etc.). E terceiro, possuem um "caráter exploratório", ou seja, procuram explorar novas possibilidades ao invés de resolver problemas já conhecidos. A abertura e o amplo espaço para interpretação proporcionado pelo uso das sondas podem gerar resultados surpreendentes e inesperados - e esses são aspectos que interessaram à área do design.

Tipicamente, as formas mais tradicionais de autodocumentação usadas nesses trabalhos são os diários e as câmeras fotográficas, que têm no exame da experiência cotidiana seu principal objetivo acadêmico (MATTELMÄKI, 2006). O uso desses e de outros instrumentos e formas de registros pessoais proporcionaria a criação de dados em situações as mais diversas - não se limitando às observações de uma única situação específica -, além de minimizar a interferência do observador na produção dos dados.

No que diz respeito a pesquisas em que os sujeitos fotografam, esse ponto é fundamental, porque a presença de um observador poderia mudar os comportamentos dos sujeitos e limitar suas escolhas de registro (MATTELMÄKI, 2006) - quando, por outro lado, o que se pretende com as sondas é "registrar o contexto das experiências à medida que elas ocorrem" (MATTELMÄKI, 2006, p.41), minimizando assim a retrospecção, as lembranças imprecisas ou as reminiscências distorcidas.

Vemos, aqui, uma possível relação entre os conceitos que sustentam o uso das sondas culturais, para o registro de aspectos da vida cotidiana à medida que ocorrem, com a noção de contextos emergentes, proposta pela perspectiva da aprendizagem situada (ROGOFF, 1984; SCRIBNER, 1984). Isso porque, para a aprendizagem situada, contexto é diferente de cenário e é lido como tendo um fundamento histórico e processual, como algo que só é possível de ser caracterizado quando chegamos nele. Nessa perspectiva, o mundo social se configura como tal, em função de se constituir na relação de pessoas numa "ação situada [...] em um cenário cultural" 
(BRUNER, 1997, p.27). Configura-se, portanto, como algo dinâmico, mutável e nunca fixo ou prédefinido (ROGOFF, 1984; SCRIBNER, 1984), enfim, como o próprio material produzido pelas sondas culturais.

De um modo geral, a configuração de uma sonda cultural varia em função dos objetivos que se pretende atingir, e seus kits são criados em função desses objetivos (JUDICE \& JUDICE, 2009). Assim temos, por exemplo, sondas formadas por materiais os mais diversos, como: máquinas fotográficas, gravadores de voz, diários, cadernos, canetas coloridas, bloquinhos de nota, cartões postais, bonecas, caixas, tesouras, mapas, jogos de encaixe, ou o que mais possibilitar a criação dos dados que os pesquisadores desejam. Além desses materiais, as sondas contam com orientações para a execução de tarefas específicas, como tirar fotografias, escrever diários, responder a perguntas, desenhar mapas, fazer colagens, etc.

Para responder à pergunta sobre se "as sondas poderiam facilitar a investigação da experiência diária das pessoas?" (MATTELMÄKI, 2006, p.12), apresentamos como resposta trabalhos desenvolvidos em 2010 por alunos do Instituto Faber-Ludens de Design de Interação (http://faberludens.com.br/) e realizado com crianças no Paraná. Esse estudo demonstra tanto a variabilidade de materiais possíveis de serem transformados em sondas, como também a variedade de dados que podem advir do uso desse material. Naquela ocasião, com o objetivo de reunir dados para um projeto de alfabetização digital, os pesquisadores entregaram às crianças e suas famílias materiais como a "Cuca Fresca", o "Baú de Coisas Legais" e o "Nham Nhoc".

O "Cuca Fresca” era uma boneca plástica, com um orifício na cabeça, no qual a criança, seus pais e professores deveriam colocar papeizinhos coloridos, escritos com coisas que gostariam que estivesse "na cabeça das crianças". Ao ser devolvida, a cabeça da boneca estava cheia de perguntas sobre coisas que a criança não sabia e bilhetes dos pais e professores demonstrando suas preocupações com a criança. O "Nham Nhoc" consistia em dois sacos plásticos transparentes e vedáveis, nos quais a criança deveria depositar pequenos pedaços de comida, no momento de suas refeições. No saco "Uhmmm" deveria colocar o que gostava e no "Écat", as comidas que não lhe agradavam. O resultado da sonda indicou, para surpresa da mãe, que a criança não gostava de determinados alimentos que lhe eram oferecidos regularmente. Já o "Baú de Coisas Legais" era uma caixa de sapato, revestida com papel branco, com cadeado e alças feitos de emborrachado colorido, contendo um conjunto de canetinhas hidrográficas coloridas. Foi entregue a uma criança com o objetivo que ela guardasse seus objetos imaginários. A sonda retornou coberta de desenhos feitos pela criança com a ajuda de seu pai. 
Como já assinalamos anteriormente, um dos objetivos das sondas é que, de posse do material entregue pelo pesquisador e após um encontro em que são dadas orientações relativas à proposta do trabalho, o usuário possa registrar informações, de maneira parcialmente livre, durante um tempo determinado - período depois do qual, as sondas voltam para o pesquisador e são analisadas. Essa proposta de investigação se propunha mais a funcionar como uma ferramenta de aprendizado que a criar dados precisos ou definitivos. Esse tipo de metodologia talvez não gere a possibilidade de uma leitura objetiva do mundo - de um modo geral são usadas quando é possível manter certa 'informalidade' na criação dos dados -, mas busca alcançar o ponto de vista do sujeito investigado, a partir de "suas crenças e desejos, suas preferências estéticas e suas preocupações culturais" (GAVER, DUNNE \& PACENTI, 1999, p.25).

No caso das sondas acima descritas, elas foram entregues aos sujeitos e, entre cinco e sete dias depois, recolhidas de volta. No dia do retorno das sondas foram feitas entrevistas em que os pesquisadores constataram que aqueles três instrumentos interferiram na relação familiar. Os dados revelaram, por exemplo: a surpresa da mãe diante de algumas perguntas que a filha colocou na "Cuca Fresca"; o desconhecimento da outra mãe sobre o fato de que comidas rotineiras do cardápio familiar eram consideradas "écat" pela criança; e a evidente a convivência da criança com seu pai quando da confecção conjunta do "Baú de coisas legais". Essas informações sugerem que aquelas três sondas culturais, além de gerarem informações, criaram um movimento de produção de sentidos acerca do que havia sido solicitado aos sujeitos - funcionando como uma espécie de "pesquisa incidental".

\section{INOVAÇÃO METODOLÓGICA PARA A PESQUISA COM CRIANÇAS: UM ESTUDO DA PSICOLOGIA}

A caracterização acima descrita diz respeito a uma metodologia criada e usada na área específica do design. O que pretendemos aqui é demonstrar como, inspirados nessas sondas originais, podemos transformá-las em instrumento para pesquisas com crianças, notadamente, nas áreas da psicologia e da educação. Dois pontos principais e interligados justificam o uso das sondas culturais em pesquisas nestas áreas: a questão do uso e a possibilidade do lúdico.

A variabilidade de materiais das sondas culturais e a necessidade de que o sujeito que recebe a sonda os use são fundamentais para gerar um envolvimento com o jogo da pesquisa - mais particularmente, quando falamos de pesquisas com crianças, mas não exclusivamente com esta população. O uso de materiais diversos e lúdicos pode ser um elemento importante para a geração de descrições do mundo feitas por crianças, afinal, "os objetos ditam à criança o que ela tem que 
fazer" (VYGOTSKY, 1989, p.110). E ao ditarem as regras, orientam sobre como devem prosseguir no jogo da pesquisa - que, como qualquer outro jogo é

uma atividade ou ocupação voluntária, exercida dentro de certos e determinados limites de tempo e de espaço, segundo regras livremente consentidas, mas absolutamente obrigatórias, dotado de um fim em si mesmo, acompanhado de um sentimento de tensão e alegria e de uma consciência de ser diferente da vida quotidiana. (HUIZINGA, 1996, p.33).

Sendo assim, e procurando responder à pergunta sobre "que tipo de tecnologias podem ser apropriadas para o Homo Ludens?" (GAVER, 2001), apresentamos um modelo de investigação (de estratégia metodológica) capaz de gerar, em crianças participantes de pesquisas, um tipo de envolvimento perto do que poderia ser considerado uma brincadeira.

Sobre esse tipo de pesquisa que se parece com uma brincadeira, é importante considerar (GAVER, 2002) a noção de Homo Ludens (HUIZINGA, 1996) como um antídoto aos pressupostos de que a tecnologia (e os métodos tradicionais de criação de dados de pesquisa, de um modo geral) seria capaz de fornecer sempre informações claras e soluções eficientes para problemas práticos. Isso porque o jogo, longe de ser uma forma de entretenimento sem sentido (mindless), é uma forma de nós, tanto adultos como crianças, nos envolvermos com o mundo e aprendermos sobre ele e sobre nós mesmos (GAVER, 2002) - isso porque, brincando com ideias e coisas, podemos descobrir e desenvolver novas maneiras de criar e novas perspectivas para a resolução de problemas.

Destacando a possibilidade de "alegria que está indissoluvelmente ligada ao jogo" (HUIZINGA, 1996, p.24) e a ideia de que o uso de recursos lúdicos de pesquisa (que, por assim dizer, falam na língua da criança) poderiam gerar dados significativos, demonstramos que, se nos jogos de pesquisa as regras viessem acompanhadas de um caráter lúdico (de brincadeira, de faz de conta, p.ex.), poderíamos justificar o uso de sondas culturais em pesquisas no campo da psicologia com crianças. Desse modo, teríamos a possibilidade de justificar uma metodologia em que pesquisadores pudessem compartilhar com crianças a imersão em um jogo lúdico de pesquisa.

Fazendo isso, verificamos que as sondas culturais se configuram como uma estratégia de investigação que amplia possibilidades de respostas das crianças: a usabilidade dos itens reduz as expectativas possivelmente geradas por uma pesquisa "tradicional" e a estética lúdica passa a ser um diferencial capaz de gerar interesse e engajamento na pesquisa. 
Em função do que foi dito, desenvolvemos uma sonda cultural (configurada como um jogo chamado "Dia-a-Dia", e formada por um kit com uma caixa contendo máquina fotográfica, lápis de cor, lápis grafite, papeis e instruções) que foi usada como método numa pesquisa com crianças e verificamos que ela se revelou como um instrumento capaz de, em função de sua própria execução, produzir sentidos acerca da vida cotidiana, para os sujeitos da pesquisa, e atender ao objetivo de verificar como crianças produzem sentidos em seu dia-a-dia.

\section{PROCESSOS DE PRODUÇÃO DE SENTIDOS NA VIDA COTIDIANA}

Para tanto, esta pesquisa se baseou no conceito de processos de produção de sentido, entendidos como sendo fenômeno amplos, não unicamente cognitivos, ligados aos usos que fazemos da linguagem e associados tanto às relações interpessoais, quanto às formas de funcionamento das pessoas em contextos contingenciais e emergentes.

Os processos de produção de sentidos ocorrem em função dos usos que fazemos da linguagem em nossa vida diária - a linguagem é, portanto, um meio pelo qual estabelecemos nossas relações no mundo e com o mundo. Desse modo, o que produz sentidos são as nossas possibilidades relacionais e comunicativas e não as (puras) palavras, afinal, "não podemos adivinhar como uma palavra funciona. Temos de ver seu emprego e aprender com isso" (WITTGENSTEIN, 1989, p.114, $\S 340)$.

Nossa linguagem é, portanto, histórica, e somos sujeitos regulados por nossas relações no mundo - relações semióticas e discursivas, nas quais os sentidos são compartilhados. Entendemos também que "as origens do significado estão fundadas no espaço intersubjetivo contingencialmente formado entre um sujeito, um outro e um objeto comum, sobre o qual se fala" (CORNEJO, 2008, p.171) e que "a compreensão da linguagem é produzida se e somente se existe uma experiência comum. Consequentemente, intersubjetividade é aqui definida como o espaço onde nós somos seres-no-mundo-com-outros" (CORNEJO, 2008, p.174).

Compreendendo esses pontos, consideramos que "usar palavras é agir, dentro de contextos, com determinados objetivos. É fazer parte de uma 'forma de vida', estar inserido na vida social" (BEZERRA JR., 2001, p. 149). Então, linguagem implica em usos e formas de vida. Quando falamos em usar uma linguagem, falamos em encontrar vocabulários que gerem efeitos de subjetividade (afetos, identidade, redescrições do mundo) e quando situamos linguagem como ação, apontamos para seu elemento performativo e, então, podemos afirmar que "o eu humano é criado pelo uso de um vocabulário" (RORTY, 2007, p.31), que nós habitamos na linguagem, que ela "cria 
realidades" (ECHEVERRÍA, 2007, p.35) e que "mudar nossa maneira de falar é mudar, para nossos propósitos, aquilo que somos" (RORTY, 2007, p.52).

Entendendo esses aspectos, a noção de vida cotidiana se circunscreve sustentada na ideia de que é nas relações do dia-a-dia e no fluir das ações cotidianas, com seus padrões de permanência e com suas rupturas (ECHEVERRÍA, 2007), que elaboramos nossas histórias de vida e nos constituímos como sujeitos (MANNONI, 1981; DOLTO \& NASIO, 2008; EMILIANI, 2009; WILLIS, 1990; HELLER, 2008; CERTEAU, 2009; BRUNER, 1997; ROSSLER, 2004).

E, a partir daí, é possível interpretar a linguagem das ações cotidianas como narrativas do presente (BRUNER,1997; DE CONTI \& SPERB, 2009; CASTRO, 2001), conceito este, por sua vez, fundamental para a ampliação das reflexões sobre o conceito de processos de produção de sentidos na vida cotidiana.

\section{USO DA FOTOGRAFIA PARA PRODUÇÃO DE SENTIDOS SOBRE A VIDA COTIDIANA}

Em função dessas marcações conceituais, desenvolvemos uma pesquisa onde a fotografia foi usada como uma estratégia metodológica (uma máquina fotográfica fez parte do kit da sonda cultural entregue às crianças) de criação de dados capaz de gerar aos próprios processos de produção de sentidos. Para tanto, a fotografia é aqui entendida como estando ligada tanto ao ato que a faz ser, quanto à palavra que a interpreta (BARTHES, 1984, 2008; DUBOIS, 2009; SOUZA \& LOPES, 2002; SONTAG, 2004; CARNICEL, 2002).

A fotografia, como recurso gerador de um processo de produção de sentidos, é entendida como uma extensão do tempo, mais que apenas a extensão do nosso olhar ou de nossas lembranças. Isso porque "o que a Fotografia reproduz ao infinito só ocorre uma vez: ela repete mecanicamente o que nunca mais poderá repetir-se existencialmente. [...] é o Particular absoluto, a Contingência soberana.” (BARTHES, 1984, p.13). Portanto, mais do que uma retina artificial, com esses desenhos produzidos pela luz ao se apertar um botão, temos o registro, não apenas da imaginação ou da memória e da história humana, mas de sua existência contingente e da inexorabilidade do tempo.

Com os recursos da tecnologia da imagem podemos construir o retrato histórico de um povo, de um tempo, de um lugar; com a fotografia, podemos registrar olhares que descrevem tanto $o$ que se vê, quanto o como se vê; podemos retratar formas de vida; podemos registrar a vida cotidiana e falar dos sentidos dessa vida a partir de imagens. Deste modo, a fotografia pode se 
constituir como um recurso para interpretarmos os sentidos do humano. Sontag (2004) afirma que as fotos, ao ensinarem um novo código visual, "modificam e ampliam nossas ideias sobre o que vale a pena olhar e sobre o que temos o direito de observar. Constituem uma gramática e, mais importante ainda, uma ética do ver" (SONTAG, 2004, p.13).

\section{USO DE SONDAS CULTURAIS EM PESQUISA COM CRIANÇAS: METODOLOGIA, ANÁLISE E DIVERSÃO}

A partir dessa rede conceitual, foram elaborados os dois objetivos principais da nossa pesquisa. O primeiro: caracterizar como se dá o processo de produção de sentidos na vida cotidiana de crianças; e o segundo: elaborar uma prática de produção de dados em psicologia capaz de contribuir para o engajamento de crianças na proposta de pesquisa, de maneira lúdica, através de um jogo de pesquisa.

Para o estabelecimento desses objetivos, foi levada em consideração a ideia de que, com descrições da cotidianidade feitas por crianças, a partir de seus registros fotográficos, seria possível "ver" (pelo ponto de vista de cada criança) como se processa a produção de sentidos em suas vidas diárias e "ouvir" (dando voz às crianças) o que elas teriam a dizer sobre os sentidos de sua vida diária.

Criamos, então, a sonda cultural, o "jogo de pesquisa" intitulado "Dia-a-Dia", que foi entregue às crianças no formato de uma caixa contendo: um folheto de instruções, no formato de texto ficcional, orientando sobre as regras do jogo de pesquisa, uma câmera fotográfica descartável, um caderno de desenho, uma coleção de lápis de cor e lápis grafite.

Quatro crianças colaboraram como sujeitos da pesquisa: dois meninos e duas meninas, com idades entre 9 e 11 anos, de situações sócio-econômicas distintas, estudantes de escolas públicas e privadas, residentes na Região Metropolitana de uma capital do Nordeste brasileiro.

As crianças colaboradoras foram convidadas a jogar o jogo "Dia-a-Dia". Para jogar este jogo (uma sonda cultural), elas o receberam, em um encontro com a pesquisadora, e foram orientadas (a partir da leitura das "instruções do jogo") a fotografar (e a desenhar) sua vida diária a orientação era a de que fotografassem o que quisessem, o que fazia e o que não fazia sentido no seu dia-a-dia.

As crianças ficaram com o "Dia-a-Dia" por uma semana e então devolveram a caixa com os dados produzidos (seus desenhos e as fotografias a serem reveladas). Depois de impressas e organizadas na sequência em que foram tiradas, as fotos foram devolvidas às crianças, em um 
álbum. Cada criança recebeu seu próprio álbum de fotografia. Diante das fotos que observavam, as crianças conversaram com a pesquisadora sobre suas produções - num modelo de estudo que classificamos como imagético-discursivo. Com isso, buscamos dar voz às crianças, fazendo uma escuta do que tinham a nos dizer (LAJONQUIÈRE, 2010) e buscando compreender os sentidos por elas criados sobre o cotidiano infantil, a partir do seu próprio ponto de vista.

Para a análise e interpretação dos dados, nos baseamos no entendimento de que é no dia-adia que as crianças começam a elaborar os primeiros sentidos de seu ser-no-mundo-com-outros (CORNEJO, 2008). Pedindo às crianças para fotografarem coisas significativas na sua vida diária, e depois ouvindo o que tinham a nos dizer sobre essas imagens, foi possível usar os dados de um ato fotográfico-narrativo para alimentar um ato interpretativo de produção de sentidos.

Já de posse dos dados fotográficos e discursivos criados pelas crianças (as conversas foram gravadas em áudio e vídeo e transcritas), foi realizada uma sistematização gráfica dos processos de produção de sentido de cada um dos sujeitos da pesquisa.

Essa sistematização foi feita em função de três aspectos: 1) onde foram feitas as fotografias (ambiente), 2) quem ou o quê aparecia nas fotos, 3) quem fez as fotos e 4) como essas imagens eram apresentadas - se de maneira mais literal, como em fotos de objetos ou de pessoas fazendo poses; ou se de maneira mais pragmática, retratando ações e relações. As sequências fotográficas de cada criança foram classificadas em função dos seus núcleos narrativos, e transformadas em gráficos.

A disposição dos dados nos gráficos possibilitou o estabelecimento de padrões, que foram classificados em função da variedade de imagens e em função do modo como a sequência fotográfica foi feita. A linearidade ou a descontinuidade, e a variedade ou a repetição, em relação às sequências fotográficas das crianças, apontaram para os modos como elas produzem sentidos sobre o seu dia-a-dia.

A interpretação dos dados foi feita a partir da análise da relação entre as fotografias e a narrativa das crianças acerca dessas imagens. Os resultados demonstraram que, a despeito de todas as crianças situarem parte de suas fotografias nos espaços doméstico e escolar, houve variação tanto no que elas fotografam, quanto no modo como o fizeram. E essa variação, ao apontar para os diferentes modos de produção de sentidos em suas experiências cotidianas, sugere a possibilidade de estabelecimento de categorias de análise e de padrões para a leitura desses processos de produção de sentidos (os registros dos desenhos das crianças serviram como complemento para a 
compreensão do dia-a-dia das crianças, visto que muitos deles ou eram repetição dos temas das fotografias, ou detalhamento de situações que não foram fotografadas).

A análise imagético-discursiva apontou para a possibilidade de que, dando voz às crianças (através de suas narrativas do presente), e vendo o mundo por seus olhos (através de suas fotografias) podemos construir reflexões em psicologia capazes de compreender a criança do nosso tempo. E esta compreensão nos encaminha para possibilidades de ampliar compreensões e gerar intervenções ligadas ao universo infantil, tanto no âmbito das práticas psicológicas, quanto no das práticas educacionais.

\section{INOVAÇÃO METODOLÓGICA}

Enquanto os pesquisadores da área do design, com o retorno de suas sondas, tiveram a possibilidade de desenvolver conceitos de novos produtos, com base nas respostas dos participantes que usaram suas sondas culturais (GAVER, 2001). No nosso caso, o desenvolvimento de uma pesquisa com sondas culturais e a análise dos seus dados puderam indicar que, além de caminhos para a criação de estratégias inovadoras de pesquisa com crianças, esta estratégia de investigação é capaz tanto de gerar uma compreensão mais abrangente sobre os processos de produção de sentidos na vida cotidiana de crianças (e consequentemente, sobre uma psicologia do desenvolvimento infantil, baseada em narrativas do presente), como de proporcionar o desenvolvimento de novas práticas profissionais (nos diversos campos da psicologia e da educação, por exemplo), mediadas pelo uso de sondas culturais.

Com esta proposta metodológica, criamos uma oportunidade de construir um diálogo com crianças, a partir de uma estratégia lúdica de pesquisa, capaz de nos fazer produzir uma interpretação sobre os sentidos em suas vidas cotidianas.

Os dados criados nos levaram a concluir que esta estratégia investigativa pode vir a contribuir para outros estudos e reflexões que vêm se desenvolvendo sobre a infância no momento atual. Além disso, consideramos que o uso do "Dia-a-Dia", nosso jogo de pesquisa, pode se estender para além do âmbito da pesquisa acadêmica, em direção a diversos cenários de intervenção. 


\section{REFERÊNCIAS}

BARTHES, R. A câmara clara: nota sobre a fotografia. 11.ed. reimpressão. Trad. J. C. Guimarães. Rio de Janeiro: Nova Fronteira, 1984.

BARTHES, R. Aula. 9.ed.Trad. L. Perrone-Moisés. São Paulo: Cultrix, 2008.

BEZERRA JR., B. (2001). O lugar do corpo na experiência do sentido: um perspectiva pragmática. In: BEZERRA JR, B. e PlASTINO, C. A. (orgs.). Corpo, afeto e linguagem: a questão do sentido hoje. Rio de Janeiro: Rios Ambiciosos, 2001.

BRUNNER, J. Atos de significação. Trad. S. Costa. Porto Alegre: Artes Médicas, 1997.

CARNICEL, A. (2002). Fotografia e inquietação: uma leitura da imagem a partir da relação fotógrafo-fotografado. Resgate, Campinas (SP), n.11, p. 41-54.

CASTRO, L. R. Da invisibilidade à ação: crianças e jovens na construção da cultura. In: na construção da cultura. Rio de Janeiro: FAPERJ: Nau Editora, 2001. Crianças e jovens

CERTEAU, M. A invenção do cotidiano: artes de fazer. 16.ed. Trad. E. F. Alves. Petrópolis: Vozes, 2009.

CORNEJO, C.(2008). Intersubjectivity as co-phenomenology: from the holism of meaning to the being-in-the-worldwith-others. Integrative Psychological and Behavioral Science, n.42, v.2, p. 171-178.

DE CONTI, L. e SPERB, T. M. (2009). A composição de narrativas pela dupla terapeuta-paciente: uma análise da sua organização e da sua sequência de ações. Psicologia: Reflexão e Crítica, Porto Alegre, n.1, v.22, p. 119-127, 2009.

DOLTO, F. e NASIO, J.-D. A criança do espelho. Trad. A. Telles. Rio de Janeiro: Zahar, 2008.

DUBOIS, Philippe (2009). O ato fotográfico e outros ensaios. 12. ed. Trad. M. Appenzeller. Campinas: Papirus, 2009.

ECHEVERRÍA, R. (2007). Ontología del lenguage. Buenos Aires: Granica: Juan Carlos Saez Editor, 2007.

EMILIANI, Francesca (2009). A realidade das pequenas coisas: a psicologia do cotidiano. Trad. R. L. Bottini. São Paulo: Senac, 2009.

GAVER, B.; DUNE, T.; PACENTI, E. (1999). Cultural Probes. Interactions, january-february, p.21-29, 1999.

GAVER, Bill (2001). Designing for ludic aspects of everyday life. ERCIM News: 47. 2001. Disponível em: http://www.ercim.eu/publication/Ercim_News/enw47/gaver.html. Acesso em: 12 de março de 2011.

HARRÉ, R.; GILletT, G. (1999). A mente discursiva: os avanços da ciência cognitiva. Trad. D. Batista. Porto Alegre: Artmed, 1999.

HELlER, A. (2008). O cotidiano e a história. 8.ed. Trad. C. N. Coutinho e L. Konder. São Paulo: Paz e Terra, 2008.

HUIZINGA, J. (1996). Homo Ludens: o jogo como elemento da cultura. 4. ed. Trad. J. P. Monteiro. São Paulo: Perspectiva, 1996.

JUDICE, A.; JUDICE, M. (2009). Desenvolvimento de pacotes de sondas culturais para o estudo em comunidades vulneráveis em Duque de Caxias, Rio de Janeiro. Anais do V Congresso Internacional de Pesquisa em Design, Bauru (SP), 2009, p. 1863-1870.

LAJONQUIÈRE, L. de (2010). Figuras do infantil: a psicanálise na vida cotidiana com as crianças. Petrópolis: Vozes, 2010.

LOURENÇO, O. O perigo das palavras: uma lição de Wittgenstein para psicólogos e educadores. Análise psicológica. n.2, v.17, 1999, p. 253-263.

MANNONI, M. A primeira entrevista em psicanálise. Tradução Roberto Cortes de Lacerda. Rio de Janeiro: Campus, 1981.

MATTElMÄKI, T. (2006). Design Probes. (Publication Series of the University of Art and Design Helsinki). Vaajakoski (Finland): Gummerus Printing, 2006.

ROGOFF, B. Introduction: thinking and learning in social context. In Barbara Rogoff \& Jean Lave. Everyday cognition: its development in social context. Cambridge, Massachusetts e London: Harvard University Press, 1984.

RORTY, R. Contingência, ironia e solidariedade. Trad. V. Ribeiro. São Paulo: Martins, 2007. 
ROSSLER, J. H. (2004). O desenvolvimento do psiquismo na vida cotidiana: aproximações entre a psicologia de Alexis N. Leontiev e a teoria da vida cotidiana de Agnes Heller. Caderno Cedes, n.24, v.62, 2004, p. 100-116.

Scliar, Moacyr (2006). Roda dos Expostos. (Disponível em http://www.academia.org.br/ abl/cgi/cgilua.exe/sys/ start.htm?from_info_index=61\&infoid=1267\&sid=369, acesso em 18/ago/2011).

SCRIBNER, S. Studying working intelligence. In Barbara Rogoff \& Jean Lave. Everyday cognition: its development in social context. Cambridge, Massachusetts e London: Harvard University Press, 1984.

SONTAG, S. Sobre fotografia. Trad. R. Figueiredo. São Paulo: Companhia das Letras, 2004.

SOUZA, S. J.; LOPES, A. E. Fotografar e narrar: a produção do conhecimento no contexto da escola. Cadernos de Pesquisa, n.116, julho 2002, p. 61-80.

VYGOTSKI, L.S. A formação social da mente. 3. ed. Trad. J. Cipolla Neto, L. S. M. Barreto e S. C. Afeche. São Paulo: Martins Fontes, 1989.

WILLIS, P. (1990). Common culture: symbolic work at play in the everyday cultures of the young. Boulder e São Francisco: Westview Press, 1990.

WITTGENSTEIN, L. Investigações Filosóficas. Trad. J. C. Bruni. São Paulo: Nova Cultural, 1989. 


\section{RESUMO}

As sondas culturais são uma estratégia de criação de dados nascida na área do design, aqui apresentadas como uma estratégia metodológica inovadora e lúdica para a produção de dados de pesquisa qualitativa em psicologia com crianças. Com este estudo sobre processos de produção de sentidos na vida cotidiana de crianças, baseado em reflexões da psicologia cultural e em análises imagético-discursivas, fica demonstrado o quanto as sondas culturais se configuram como um método inovador e capaz de gerar dados consistentes e relevantes, tanto em pesquisas, como em práticas profissionais de psicólogos e educadores.

Palavras-chave: sonda cultural; inovação metodológica; psicologia e educação.

\section{CULTURAL PROBES AS A METHOD FOR DATA CREATION IN RESEARCH WITH CHILDREN}

\section{ABSTRACT}

The cultural probes are a data creation strategy, born in the design area, presented here as an innovative and playful methodological strategy to produce qualitative research data in psychology with children. In the study, developed by the author in a doctoral thesis on processes of production of meanings in the daily life of children, based on reflections of cultural psychology and on imagetic-discursive analyzes, it is demonstrated how cultural probes are configured as an innovative and capable method to generate consistent and relevant data, both in research and in professional practices of psychologists and educators.

Keywords: cultural probe; methodological innovation; psychology and education

\section{SONDAS CULTURALES COMO MÉTODO DE CREACIÓN DE DATOS EN INVESTIGACIONES CON NIÑOS}

\section{RESUMEN}

Las sondas culturales son una estrategia de creación de datos nacida en el área del diseño, presentadas aquí como una estrategia metodológica innovadora y lúdica para la producción de datos de investigación cualitativa en psicología con niños. En el estudio, desarrollado por la autora en una tesis de doctorado sobre procesos de producción de sentidos en la vida cotidiana de niños, basado en reflexiones de la psicología cultural y en análisis imagético-discursivos, queda demostrado cuánto las sondas culturales se configuran como un método innovador y capaz de generar datos consistentes y relevantes, tanto en investigaciones, como en prácticas profesionales de psicólogos y educadores.

Palabras-clave: sonda cultural; innovación metodológica; psicología y educación. 